UDC $676.011,546.824$

\title{
APPLICATION OF TITANYL SULPHATE FOR MANUFACTURING PAPER CONTAINING $\mathrm{TIO}_{2}$ FILLER
}

\author{
(c) N. Izmailova ${ }^{1}$, R. Shabiev ${ }^{I^{*}}$, A. Lorentsson ${ }^{1}$, N. Saprykina ${ }^{2}$ \\ ${ }^{1}$ Saint Petersburg State University of Industrial Technologies and Design, 4, Ivana \\ Chernykh Str., Saint Petersburg, 198095 (Russia), e-mail: ncjob@yandex.ru \\ ${ }^{2}$ Russian Academy of Sciences, Institute of Macromolecular Compounds, 32, \\ Bolshoy Pr., Saint Petersburg, 199004 (Russia), e-mail: elmic@hq.macro.ru
}

The aim of research was first, to study the interactions between components for finding out how $\mathrm{pH}$ effects on $\zeta$ potential, dewatering rate and retention of $\mathrm{TiO}_{2} / \mathrm{MCC}$ mixtures with/without titanyl sulphate in order to find a way to titanyl sulphate hydrolysis in a papermaking process. The maximum heterocoagulation interactions between $\mathrm{TiO}_{2}, \mathrm{MCC}$ and $\mathrm{TiOSO}_{4}$ were revealed in the $\mathrm{pH}$ range 4.4-5.6. Second, handsheets made from refined chemical pulp, titanyl sulphate and $\mathrm{TiO}_{2}$ at $\mathrm{pH}$ 4.4 were investigated. The handsheets were formed and studied conventionally and with scanning electron microscopy (SEM). It was shown that titanyl sulphate hydrolysis leads to formation of translucent polymer film covering the fibres and $\mathrm{TiO}_{2}$ particles. The maximum first-pass ash retention reached is lower than its values usually obtained with an organic polymer. Addition of titanyl sulphate led to higher strength, but lowered opacity and brightness compared to a reference sample. The use of low dosage of titanyl sulphate together with a filler improved air permeability. As there exist certain advantages/disadvantages of titanyl sulphate application, extended research is needed to find suitable conditions for its applying to mass paper and board grades production.

Keywords: Titanyl sulphate, titanium dioxide, polynuclear hydrolysis compounds, microelectrophoresis, microcrystalline cellulose, handsheets.

The authors thank the Russian Ministry of Education and Science for the financial support of production and evaluation of handsheets within the State Grant No 10.6052/2017/8/9.

\section{Introduction}

Uniqueness of cellulose fibres provide well recognized features to the paper products. However, their natural properties do not always meet demands for the whole range of paper grades and not fully comply with all aspects of the paper production process. Albeit the impressive results achieved by the modern paper technology there is still a room for improvement both the production process and paper properties. One of the ways to continue is finding suitable chemical additives and fillers. Addition of them can compensate insufficient fibre natural properties or even give specific unusual properties to cellulose paper, like higher wet strength, longer water-repellency, flame retardant etc. Additives are important for specialties, like decorative base paper or sack paper, and for handmade papers. To meet the desired properties to cellulose fibre materials, various components are typically added to the stock like fillers, retention aids, sizing agents, resins, specific mineral components etc [1].

\footnotetext{
Izmailova Nadezhda - $\mathrm{PhD}$ (Chem), Teacher (position) at Dept. of Environmental Protection and Rational Use of Natural Resources, e-mail: nadik-izmailova@mail.ru Shabiev Ruslan - $\mathrm{PhD}$ (Chem), Assoc. Prof. at Dept. of Paper and Board Technology, e-mail: ncjob@yandex.ru Lorentsson Alexander - PhD (Chem), Assoc. Prof. (title), Assoc. Prof. at Dept. of Environmental Protection and Rational Use of Natural Resources, e-mail: lorenss74@mail.ru Saprykina Natalia - PhD (Chem), Senior Fellow (Academic Title), e-mail: elmic@hq.macro.ru
}

When a filler is applied to the stock, its retention and performance are critical issues. It is quite important for paper containing $\mathrm{TiO}_{2}$ filler, because it is, first, among the most expensive ones, and second, it is used to produce high performance paper specialties. Instead of purely mechanical retention, which is not economically feasible due to the low first-pass ash retention and lower mechanical properties compared 
to the similar filled paper obtained with the aid of chemical retention [2]. Therefore, the chemical additive is approved to be used for retention. Nowadays the paper technology for the most popular grades relies on the use of polyelectrolytes. When they are used, the high retention is achieved [3]; however, the formation and dewatering may suffer, felts and wires could be plugged, and the brightness may decrease either due to diffusion of the light on the polyelectrolyte/filler interface or by the chemical reaction between cationic polyelectrolytes and optical brighteners. As an alternative, there are available some salts of polyvalent metals, hydrolysis of them may lead to the formation of inorganic polymer-like polynuclear compounds, acting like synthetic polymers. Titanyl sulphate one of those was selected for our study. Titanyl sulphate is the famous for being an intermediate product in the commercial production of $\mathrm{TiO}_{2}$ pigments by conventional sulphate route [4]. It is also one of the strongest complexing agents, its hydrolysis compounds have a large sorption capacity and react with almost all classes of organic matters to form insoluble complexes [5]. If addition of titanyl sulphate leads to the formation of stable floccules during wastewater clarification and a well-filtered precipitate is formed, we have assumed that it can be used as a remedy for improvement of papermaking processes. Hydrolysis of titanium ions in diluted sulphuric acid is a complex physicochemical process, when the concentration of titanyl sulphate is low; the titanyl ions are present mainly in the monomeric form [4]. The chemistry of titanyl sulphate hydrolytic transition at the room temperature and low concentration can be represented as a chain of transformations leading to the formation of polynuclear hydrolysis compounds of amphoteric and hydrated hydroxide oxotitanium of a variable composition [5]. At the higher temperature, the hydrolysis chain leads to the formation of $\mathrm{TiO}(\mathrm{OH})_{2}[6]$.

There are some publications concerning titanyl sulphate mostly on obtaining of an ultrafine $\mathrm{TiO}_{2}$ powder by high-temperature hydrolysis of diluted titanyl sulphate solution in a weak acidic medium [7]. Nevertheless, there are only few publications about the possible application of titanyl sulphate hydrolysis compounds in papermaking. For example, it was proposed to obtain a new mineral phase of finely dispersed $\mathrm{TiO}_{2}$ particles during reaction of titanyl sulphate with chemical pulp by controlled hydrolysis at the temperature of $70{ }^{\circ} \mathrm{C}$ and the concentration of sulphur acid up to $0.25 \mathrm{M}$ [8]. Another suggestion was to use titanyl sulphate hydrolysis to generate a $\mathrm{TiO}_{2}$ filler with mineral talc powder carrier with subsequent filtration, drying and inciniration [9]. However, it has not been reported any proposals to use titanyl sulphate as a papermaking additive. To study the application of titanyl sulphate for manufacturing of paper containing $\mathrm{TiO}_{2}$ filler our research has been divided into two parts:

1. Studies of $\mathrm{TiO}_{2} / \mathrm{MCC} / \mathrm{Titanyl}$ sulphate mixtures to understand the interactions between the components;

2. Production and evaluation of handsheets to observe the effect gained in process and paper properties.

\section{Materials and Methods}

Materials. Titanium dioxide (CAS 13463-67-7) was a synthetic inorganic white powder of the anatase crystal form having a particle size range from 200 to $500 \mathrm{~nm}$ (GOST 9808). For the preparation of $\mathrm{TiO}_{2}$ suspension, the powder $(0.025 \mathrm{~g})$ was placed in $500 \mathrm{~cm}^{3}$ of distilled water and treated for $10 \mathrm{~min}$ in an ultrasound bath. Titanyl sulphate (CAS 13825-74-6) corresponded to a pure grade by TU 6-09-01-279-75 supplied by Reachim (Saint Petersburg, Russia). It was delivered in the form of a white powder. To prepare a titanyl sulphate solution with the concentration of $0.1 \mathrm{M}, 1.96 \mathrm{~g}$ of $\mathrm{TiOSO}_{4} \cdot 2 \mathrm{H}_{2} \mathrm{O}$ was placed into $100 \mathrm{~cm}^{3}$ of $1 \mathrm{~N}$ sulphuric acid and treated for $30 \mathrm{~min}$ in the ultrasound bath. The solution was used within $24 \mathrm{~h}$. It should be noted that the prepared solution was cloudy.

Microcrystalline cellulose (MCC, CAS 9004-34-6) was used as a cellulose model for the microelecrophoretic measurement and filtration analysis. Early in the literature, MCC was proposed as a good cellulose model [10] to study electrokinetic phenomena by this visual technique. The measurement is based on a direct microscopic observation of the particle movement. It has been used for MCC since seventies [11] and it is still used for this kind of objects because of simplicity, low operational costs and the well-recognised set-up of the method [12]. MCC was a fraction of cotton origin of industrial P grade produced by Polyeks Company (Biisk, Russia), having a particle size range from 1 to $100 \mu \mathrm{m}$ as measured by optical microscopy and proofed by scanning electron microscopy (SEM). Fig. 1 shows an image of the unscreened MCC. Prior to use, the larger particles were eliminated by sedimentation. For the preparation of MCC suspensions $2 \mathrm{~g}$ of the powder was placed in $1000 \mathrm{~cm}^{3}$ of distilled water.

The chemical pulp used for production of handsheets was obtained from Arkhangelsk pulp and paper mill. The final pulp stock consisted of northern bleached hardwood (80\%) and softwood $(20 \%)$ kraft. Prior to use they were disintegrated in a LC pulper of horizontal design with a top loading. Cellulose fibres afterwards were refined separately at a consistency of $1.5 \%$ in a LC refiner. The refiner used by the principle of operation was close to a homogenizer with a pair of stator and rotor rings equipped with bar blades. The rings were mounted in the centre of a metal cylin- 
drical housing equipped with vanes welded around the wall. The rotor ring was rotating at $1470 \mathrm{rpm}$. The pulp suspension was continuously circulated during the process under the action of centrifugal and hydraulic forces in a turbulent flow. A refining time and clearance between the blades were used as controlled variables to monitor refining output. The clearance was $0.4 \mathrm{~mm}$ and the time was $1 \mathrm{~min}$ for hardwood pulp and 0.6 $\mathrm{mm}$ and $3 \mathrm{~min}$ for softwood pulp respectively. The refined pulp stock was mixed and poured in a proportioner container where continuously being stirred at $200 \mathrm{rpm}$. The fibre consistency was $0.4 \%$. The degree of beating was measured according to ISO 5267/1 and maintained at $24 \pm 1{ }^{\circ} \mathrm{SR}$. The paper samples were formed according to ISO 5269/2. Addition of the titanyl sulphate solution was calculated based on the $40 \%$

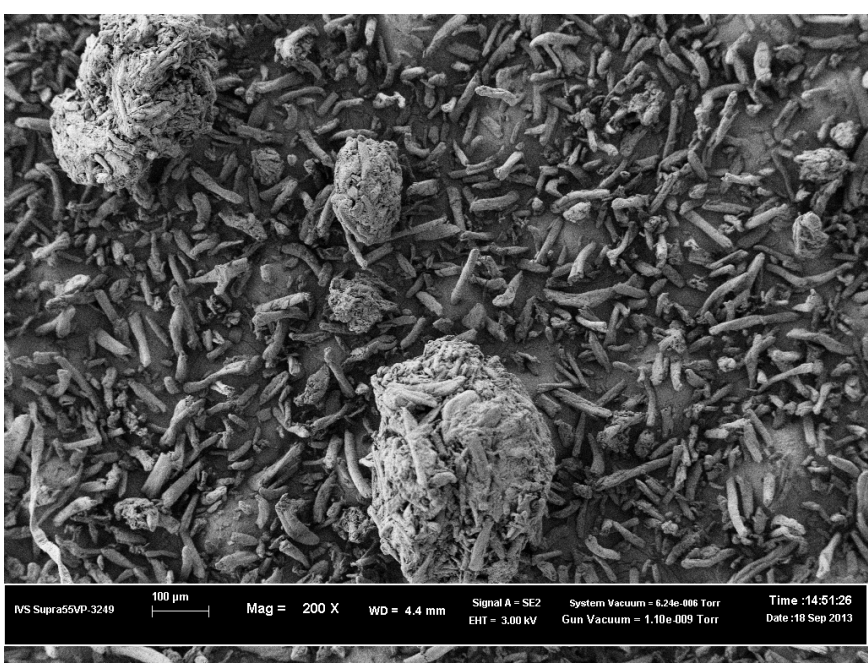

Fig. 1.-SEM image of unscreened microcrystalline cellulose (magnification $\times 200$ ) dried $\mathrm{TiO}_{2}$ equivalent content.

Zeta-potential measurement. The electrokinetic potential was determined by microelectrophoresis, in which the velocity of the studied particles was observed upon application of DC. Microelectrophoresis as a means to measure zeta potential was chosen to make a judgment for all components. In this study, a conventional modified Abramson cell was used [13], consisting of two cylindrical glass vessels connected to the bottom of a planeparallel capillary. As reversible electrodes, copper plates immersed in a saturated solution of copper (II) sulphate were used. To isolate the electrode space, an agar jelly was used. The electrokinetic potential of the particles was calculated based on the data obtained on the electrophoretic mobility by the Helmholtz-Smoluchowski equation (written in a SI form):

$$
\begin{gathered}
\varsigma=\frac{\eta \cdot U}{\varepsilon \cdot \varepsilon_{0} \cdot E}=\frac{\eta}{\varepsilon \cdot \varepsilon_{0}} \cdot v, \\
E=\frac{I}{\chi \cdot S}, \\
v=\frac{l}{\bar{\tau} \cdot E},
\end{gathered}
$$

symbols: $U$-particle velocity, $\mathrm{m} / \mathrm{s} ; E$ - gradient of the potential of the external electric field, $\mathrm{V} / \mathrm{m} ; v$-electrophoretic mobility, $(\mathrm{m} / \mathrm{s}) /(\mathrm{V} / \mathrm{m}) ; \varepsilon$-dielectric constant of the medium, $\varepsilon=81 ; \varepsilon_{0}$-permittivity of free space, $\varepsilon_{0}=8.85 \times 10^{-12}$ F/m; $\eta$-viscosity of the medium, $\eta=10^{-3} \mathrm{~Pa} \cdot \mathrm{s} ; I$-current, A; $\chi$-conductivity of the dispersion, S/m; $S$-crosssectional area of the capillary cell, $\mathrm{m}^{2} ; \quad l$-the particle path during the time $\tau, \mathrm{m} ; \bar{\tau}$-the average time of passage of the particles through $l$, s.

The measurements were carried out at a stationary layer. At least 10 particles of each sample were timed.

Filtration analysis. The filtration analysis of $\mathrm{TiO}_{2} / \mathrm{MCC} /$ Titanyl sulphate mixtures were performed using filter paper circles of $12.5 \mathrm{~cm}$ with a pore size range from 4 to $12 \mu \mathrm{m}$ according to specification. $\mathrm{TiO}_{2} / \mathrm{MCC}$ mixtures were prepared first and the titanyl sulphate solution was added afterwards. The final concentration of titanyl sulphate in the mixture was $0.1 \cdot 10^{-3} \mathrm{M}$. The measurements were carried out over a wide $\mathrm{pH}$ range from 3.2 to 6.7 following stirring the components for about $1 \mathrm{~min}$. The rate of dewatering $(V)$ of the mixtures through the filter circle was calculated based on the time of dewatering of $100 \mathrm{ml}$. A retention was estimated through the calculation of light transmittance based on intensities of light absorbance of the mixture $\left(A_{0}\right)$ and a filtrate $\left(A_{f}\right)$ at $540 \mathrm{~nm}$. The measurements were performed by using of a Leki spectrophotometer with $1 \mathrm{~cm}$ glass cells as an average of three-five tests. The visible turbidity was low enough to use the intensity of light absorbance as a method to estimate the retention. The light transmittance $(T)$ of the components by filter-paper method was calculated by the following formula: 


$$
T=100-\frac{A_{f}}{A_{O}} 100,(\%)
$$

In all tests, when the $\mathrm{pH}$ value was needed to adjust, the desired level was set by addition of either $1 \mathrm{~N}$ sodium hydroxide or sulphuric acid. The $\mathrm{pH}$ measurements were performed with a glass electrode attached to a Hanna HI 2213 pH meter.

Design of handsheets preparation, testing and characterization. The main purpose of handsheets production was to demonstrate the effect of $\mathrm{TiO}_{2} /$ Titanyl sulphate ratios on the properties. The $\mathrm{pH}$ of handsheets preparation was chosen based on filtration analysis result. Two batches of the handsheets of $140 \pm 5 \mathrm{~g} / \mathrm{m}^{2}$ to resemble thick paper grades were prepared with a normal tap water used in a forming column of a sheet former. The first batch was formed with altered dosages of $\mathrm{TiO}_{2}$ /Titanyl sulphate accordingly to the design shown in Table 1 . To manufacture a reference "free of any additives" sample it was required $4.4 \mathrm{~g}$. of oven-dried mass of the pulp stock. The necessary volume of the suspension was being corrected for each produced sample as based on the mass of square meter of test handsheets obtained. The ash content was determined by incinerating the dried samples in a muffle furnace at $900{ }^{\circ} \mathrm{C}$ following the procedure given in ISO 2144 . The first-pass ash retention (FPR) was calculated by the following formula:

$$
F P R=\left(1-\frac{C_{o}-C_{1}}{C_{o}}\right) 100
$$

symbols: $\mathrm{C}_{\mathrm{o}}-$ ash content of pulp stock, $\% ; \mathrm{C}_{1}-$ ash content of handsheets, $\%$.

It should be noted that only estimation of the filler retention of the $\mathrm{TiO}_{2} /$ Titanyl sulphate mixtures is possible. It is not entirely correct to calculate the ash content based on the residue mass on ignition expressed in $\mathrm{TiO}_{2}$, because during the dilution with water and $\mathrm{pH}$ raise of the mixture containing titanyl sulphate first the polynuclear hydrolysis titanyl sulphate compounds of variable composition are formed and only then, they are retained. Actually, the $\mathrm{TiO}_{2}$ particles from the titanyl sulphate solution are generated only during incineration.

The second batch was formed with altered dosages of titanyl sulphate at fixed dosage of $\mathrm{TiO}_{2}(2,0 \mathrm{~g})$ and fibre (oven-dried $4.4 \mathrm{~g}$.) to study the general dependence of tensile strength against ash content. This dependence was studied in the range of 1 to $10 \%$ titanyl sulphate dosages at $1 \%$ spacing. The $\mathrm{TiO}_{2}$ filled handsheets were stored away from sunlight because of possible chemical decomposition of $\mathrm{TiO}_{2}$.

The tensile index was taken as a mechanical property due to fluctuations in handsheets properties. At least five samples were prepared for each point to calculate mean values. Prior to testing, the samples were conditioned for several hours at a standard controlled temperature $\left(23^{\circ} \mathrm{C}\right)$ and humidity $(50 \% \mathrm{RH})$. The samples of each batch were tested during one day. Tensile strength was measured and the tensile index was calculated by a PC-controlled vertical Tinius Olsen tensile testing machine with $250 \mathrm{~N}$ load cell according to ISO 1924-1. Optical properties (brightness and opacity) were measured by Elrepho L\&W Spectrophotometer according to ISO 2470 , ISO 2471. The air permeability was measured by a manually operated Bendtsen tester according to ISO 5636-3 at a nominal air pressure of $1.47 \mathrm{kPa}$.

SEM images were obtained using a Carl Zeiss Supra 55 VP microscope operating at $10 \mathrm{kV}$. The spectra of chemical elements were analysed by using an Oxford Instruments INCA Energy SEM NanoAnalysis Energy Dispersive X-Ray Spectrometer (EDX) built into the Supra microscope. The Silicon Drift Detector X-Max has an active surface of $80 \mathrm{~mm}^{2}$ (it could be measured elements from Be to U).

Table 1. The design of handsheets with different dosages of $\mathrm{TiO}_{2} / \mathrm{TiOSO}_{4}$. All figures are given in grams, Ref. - the reference zero point sample.

\begin{tabular}{c|c|c|c|c|c|c}
\hline Samples & Ref. & No 1 & No 2 & No 3 & No 4 & No 5 \\
\hline $\mathrm{TiO}_{2}$ & - & 2.00 & 1.00 & 2.00 & 0.20 & 0.20 \\
Titanyl sulphate* & - & - & 1.00 & 0.20 & 0.02 & 2.00 \\
\hline
\end{tabular}

* The weight of titanyl sulphate was calculated based on dried $\mathrm{TiO}_{2}(2 / 5$ of its weight). 


\section{Results and Discussions}

\section{Effect of pH on $\zeta$-potential, retention and dewatering}

The retention of a mineral filler in cellulose suspensions mainly depends on following interrelated parameters: the particle size (shape), surface charge properties, steric effects and conditions of measurement [3]. When particles have opposite charges or zero charge it helps to achieve maximum heterocoagulation interactions between them [14]. Fig. 2 shows the effect of $\mathrm{pH}$ on $\zeta$-potential of $\mathrm{TiO}_{2}, \mathrm{MCC}$ and titanyl sulphate hydrolysis compounds. The MCC particles carried a positive charge above $\mathrm{pH} 2.0$ and the $\mathrm{TiO}_{2}$ particles were positively charged above $\mathrm{pH}$ 4.0. At $\mathrm{pH}$ greater than 5.5 all studied particles were negatively charged causes difficulties for the application of such systems at neutral papermaking. As far as $\mathrm{TiO}_{2}$ particles are tiny enough and electrostatic forces govern its interaction with other components of the suspension [15], in order to achieve the highest possible ash retention of a paper it is necessary to run the whole dependence of electrokinetic potential on a $\mathrm{pH}$. In the range of $\mathrm{pH} 4.0-5.0$ it is observed the optimum conditions for heterocoagulation while maintaining the positive charge of titanyl sulphate and the negative charge for studied particles of $\mathrm{MCC}$ and $\mathrm{TiO}_{2}$.

The electrokinetic data were confirmed by the calculation of light transmittance and dewatering rate for the mixtures reported in Table 2. By increasing $\mathrm{pH}$ from 3.2 to 6.7 it was observed a decrease in transmittance of filtrate and in dewatering rate of $\mathrm{TiO}_{2} / \mathrm{MCC}$ mixtures. It can be explained by the mutual negative charge rise. The reduction in dewatering rate for these mixtures indicates a suppressed attachment of $\mathrm{TiO}_{2}$ to $\mathrm{MCC}$ and plugging a filtration layer by the $\mathrm{TiO}_{2}$ particles during the filtration process. When titanyl sulphate was introduced into the $\mathrm{TiO}_{2} / \mathrm{MCC}^{\mathrm{mix}-}$ ture, the highest light transmittance of filtrate was observed in the range of $\mathrm{pH} 4.5-5.6$, which corresponds the retention on a filter paper of practically $99 \%$. The dewatering rate practically was not affected by titanyl sulphate addition until $\mathrm{pH}$ 5.6, when it was decreased more than twice. Only at $\mathrm{pH}$ around 4.5 it was noted still rapid drainage and almost transparent filtrate. At this $\mathrm{pH}$ the $\mathrm{TiO}_{2}$ particles are only negatively charged only slightly and titanyl sulphate compounds are yet positive. There were not observed any effects of titanyl sulphate at $\mathrm{pH} 3.2$, probably, because of strong positive charge and no affiliations of all titanium based compounds at these conditions. By increasing $\mathrm{pH}$ up to 6.2 ruined the titanyl sulphate effectiveness in the studied mixtures, only the dewatering rate was still high. The increase in dewatering rate at this $\mathrm{pH}$ is probably related to the aggregated $\mathrm{TiO}_{2}$ particles.

Table 2. The results of filtration analysis

\begin{tabular}{l|l|l|l|l|l}
\hline Mixture & pH & $A_{o}$ & $A_{f}$ & $T, \%$ & $V, \mathrm{ml} / \mathrm{s}$ \\
\hline $\mathrm{TiO}_{2} / \mathrm{MCC}$ & 3.2 & 0.432 & 0.021 & 95.1 & 0.142 \\
$\mathrm{TiO}_{2} / \mathrm{MCC} / \mathrm{TiOSO}_{4}$ & 3.2 & 0.440 & 0.018 & 96.0 & 0.132 \\
$\mathrm{TiO}_{2} / \mathrm{MCC}$ & 4.3 & 0.430 & 0.089 & 79.3 & 0.140 \\
$\mathrm{TiO}_{2} / \mathrm{MCC} / \mathrm{TiOSO}_{4}$ & 4.5 & 0.272 & 0.001 & 99.6 & 0.136 \\
$\mathrm{TiO}_{2} / \mathrm{MCC}$ & 5.3 & 0.446 & 0.128 & 71.4 & 0.158 \\
$\mathrm{TiO}_{2} / \mathrm{MCC} / \mathrm{TiOSO}_{4}$ & 5.6 & 0.342 & 0.007 & 98.0 & 0.051 \\
$\mathrm{TiO}_{2} / \mathrm{MCC}$ & 6.7 & 0.417 & 0.125 & 70.0 & 0.198 \\
$\mathrm{TiO}_{2} / \mathrm{MCC} / \mathrm{TiOSO}_{4}$ & 6.2 & 0.424 & 0.130 & 69.3 & 0.081 \\
\hline
\end{tabular}

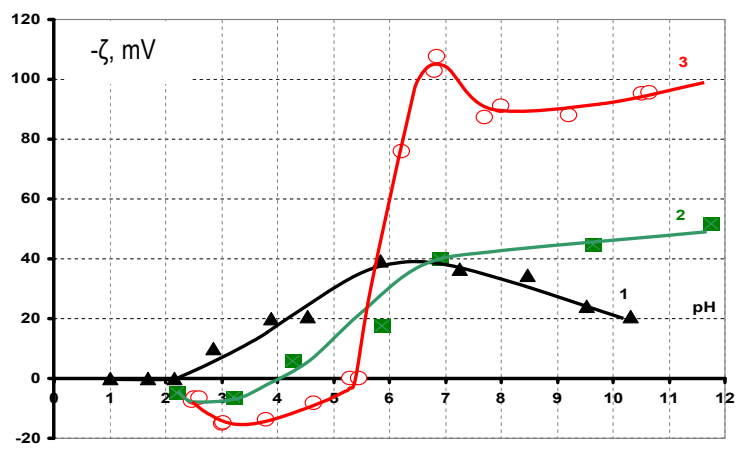

Fig. 2. Effect of $\mathrm{pH}$ on $\zeta$-potential of the particles:

1. $\mathrm{MCC} ; 2$. $\mathrm{TiO}_{2} ; 3$. Titanyl sulphate hydroxysis compounds

Considering of all studied aspects the best interaction of the components should be in the range of $\mathrm{pH} 4.0$ 5.0. Because it was too laborious to study the whole $\mathrm{pH}$ range, during handsheets making the $\mathrm{pH}$ range was maintained at $\mathrm{pH} 4.4 \pm 0.1$.

\section{Properties of handsheets}

It is expected that all properties of handsheets obtained with titanyl sulphate ought to be governed by the result of its hydrolytic transition, when the polynuclear hydrolysis compounds are formed and fixed among the fibres. The data depicted in Table 3 show, when only $\mathrm{TiO}_{2}$ filler was added to the handsheets, it was observed a moderate retention and decreased tensile properties. It is commonly caused by termination of fibre-fibre bonding. At the same time, the higher opacity and brightness have been achieved comparing to a reference sample contain- 
ing no $\mathrm{TiO}_{2}$. It should be noted that the $\mathrm{TiO}_{2}$ retention is highly dependent on a $\mathrm{pH}$, a trial sample made of the same furnish at a neural $\mathrm{pH}$ had shown the $\mathrm{TiO}_{2}$ retention as low as $20 \%$. Addition of titanyl sulphate more than doubled the ash content due to increased retention. Nevertheless, the retention with conventional polyelectrolytes is usually a bit higher as known [16]. Besides the increased retention that is quite beneficial for any additive, it was observed a contradictory effect in terms of optical properties. The brightness and opacity of the handsheets were both decreased in all instances whereas titanyl sulphate was added. This result could be a consequence of densification, coagulation and flocculation of all particles and ions in the aqueous medium. Such behaviour of the additives usually is undesirable for filled grades, such as printing and writing, but could be a specific advantage for the others. At $\mathrm{pH} 4.4$ the addition of titanyl sulphate led to an improvement of physical properties. This phenomenon is beneficial for packaging grades. The more titanyl sulphate was added, the higher strength was. It was observed a typical tendency towards decrease in the air permeability whereas the tensile strength was increased. It is likely due to the more closed pore structure was being formed. As it well known that the intensive fibre bonding leads to porosity increase. When titanyl sulphate and $\mathrm{TiO}_{2}$ were added together in minor dosages, the strength of the handsheets remained unchanged, whilst the air permeability was greatly improved. This effect belongs to the titanyl sulphate hydrolysis reaction, which cause preflocculation of $\mathrm{TiO}_{2}$ particles and fibre fines. This phenomenon usually deteriorates drainage. As far as the highest dosages of titanyl sulphate were applied, the tensile strength was much higher comparing to the reference sample. The samples formed could be characterized as having the lowest air permeability and the highest transparency. It took several minutes to form them in a sheet forming column. The handsheets looked yellow and transparent. Hydrolysis of titanyl sulphate apparently causes the forming of new bonds that helps to prevent the normal decrease in tensile properties due to a breakage of fibre-fibre H-bonds, whereas the ash content is increased. It should be taken into account that interactions between the components in the mixture took place in an acidic medium that helps the action of attractive forces. However, the increase in $\mathrm{pH}$ as a fact of dilution of pulp stock with a tap water in a sheet former caused the formation of polynuclear oxotitanium compounds. The bond links of them contribute to the paper strength.

As it is seen at Fig. 3 in the titanyl sulphate dosage range from 1 to $10 \%$ the ash content of the handsheets was increased from 22 to $34 \%$. The more titanyl sulphate was added the more ash content was. It is worth saying that quite effective dosage of titanyl sulphate was at the beginning, just $1 \%$ caused a growth in the ash content from $15 \%$ (see No 1 table 3) up to $22 \%$ (see $1 \%$ X-axe fig. 3). Such behaviour could be explained by the initial binding of the smallest fraction of $\mathrm{TiO}_{2}$ particles thus the hiding power decreased that leads to transparency raise. This increase was observed while maintaining the equal tensile properties. Further growth in the ash content resulted in decreased paper strength. Although it is known, i.e. an increase in $5 \%$ of the ground calcium carbonate filler cause a reduction of more than $10 \%$ of the paper strength [1, P. 34]. Usually the tendency of the tensile strength decrease due to the ash content increase is associated with a reduction in the total number of total fibre-fibre bondings. The curve shape shows that the major changes in paper properties happened between 2 and $4 \%$, and after $6 \%$. Certain changes could be explained by an increase in the degree of fibre involvement in active bonding with the polynuclear oxotitanium compounds.

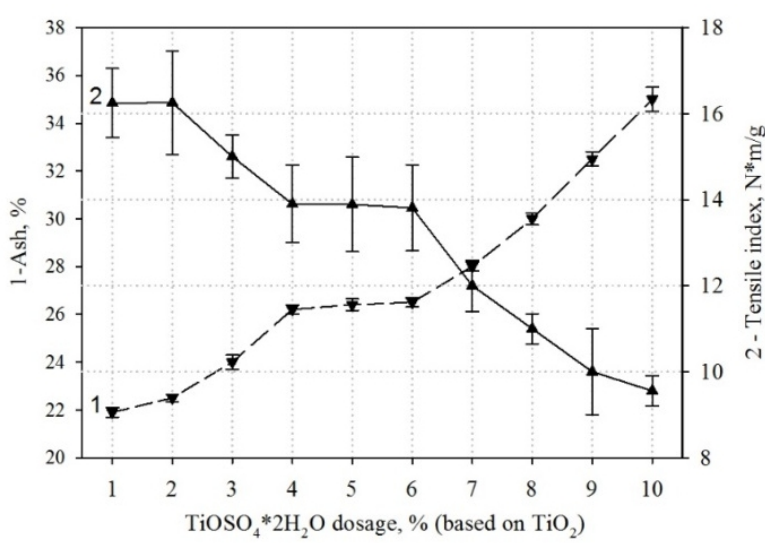

Fig. 3. The influence of titanyl sulphate dosage, calculated in $\%$ of dried $\mathrm{TiO}_{2}$ (2/5 of its weight), on the ash content (1) and tensile strength index (2) of handsheets. Fixed amount of $\mathrm{TiO}_{2}$ was added $(2.0 \mathrm{~g})$
Table 3. Ash content, first-pass retention, Bendtsen air permeability, Tensile index, Opacity (O), Brightness (B) of $140 \pm 7 \mathrm{~g} / \mathrm{m}^{2}$ handsheets being prepared with different ratios of $\mathrm{TiO}_{2} / \mathrm{TiOSO}_{4}$ (at pH $4.4 \pm 0.1$ )

\begin{tabular}{c|c|c|c|c|c|c}
\hline No. & $\begin{array}{c}\text { Ash, } \\
\%\end{array}$ & $\begin{array}{c}F P R \\
, \%\end{array}$ & $\begin{array}{c}\text { Air, } \\
\mathrm{ml} / \mathrm{min}\end{array}$ & $\begin{array}{c}\mathrm{TI}, \\
\mathrm{N} / \mathrm{m} / \mathrm{g}\end{array}$ & O, \% & $\mathrm{B}, \%$ \\
\hline Ref & - & - & 1450 & 25.4 & 89.7 & 84.8 \\
1 & 15.2 & 33 & 1500 & 16.3 & 99.2 & 95.0 \\
2 & 27.0 & 61 & 1300 & 20.4 & 78.5 & 77.2 \\
3 & 36.6 & 73 & 1400 & 11.0 & 92.5 & 93.4 \\
4 & 2.5 & 50 & 1800 & 25.3 & 88.1 & 83.4 \\
5 & 21.1 & 42 & 1150 & 28.8 & 65.5 & 73.3 \\
\hline
\end{tabular}




\section{SEM analysis of handsheets}

SEM image (Fig. 4) of the handsheets when only $\mathrm{TiO}_{2}$ filler was added shows that these particles are unevenly placed mainly in the pores of a paper sheet, no spreading between fibres is observed. There are practically no $\mathrm{TiO}_{2}$ particles being attached to the surface of cellulose fibres. It could be concluded that retention of $\mathrm{TiO}_{2}$ takes place mainly due to mechanical means, and deteriorates with an increase in a $\mathrm{pH}$ value due to increased surface charge and the action of repulsion forces. Certainly, the filler retention also depends on the specific surface, i.e. the degree of refining, it is related to the steric effect of microfibrills. The dependence on refining is explained by the preferential adsorption of $\mathrm{TiO}_{2}$ on fibrils and small filaments rather than on fibres [15]. The presence of fibrils makes cellulose fibres different from the MCC particles taken as a cellulose model.

Fig. 5 shows the agglomerated particles of $\mathrm{TiO}_{2}$ in the net of a translucent film of titanyl sulphate hydrolysis compounds which was formed between the fibres and the $\mathrm{TiO}_{2}$ particles. The presence of these compounds containing titanium was confirmed by EDX microanalysis. The results being measured in different locations show this film consists of 42 to 45 mass\% titanium as a chemical element. This titanium content range demonstrates the polymeric character of the film. This range corresponds the polymer chain structure of polynuclear oxotitanium compounds with a formula of $\left(-\mathrm{Ti}(\mathrm{OH})_{2}-\mathrm{O}-\right)_{\mathrm{n}}$. We assume for our concentration and $\mathrm{pH}$ ranges, the following reaction of titanyl sulphate hydrolysis may take place:

$$
n \mathrm{TiOSO}_{4}+(n+1) \mathrm{H}_{2} \mathrm{O} \rightarrow\left(-\mathrm{Ti}(\mathrm{OH})_{2}-\mathrm{O}-\right) n+n \mathrm{H}_{2} \mathrm{SO}_{4}
$$

Thus, the introduction of titanyl sulphate greatly improves the retention of $\mathrm{TiO}_{2}$ in the handsheets while a decreased tensile strength was compensated by forming of polynuclear oxotitanium compounds bonds of polymer character between fibres and $\mathrm{TiO}_{2}$ particles.

It is not recommended to use a high dosage of titanyl sulphate because of the suffering of dewatering rate during the sheet forming, the poor optical properties are also issue to consider the titanyl sulphate efficiency of application.

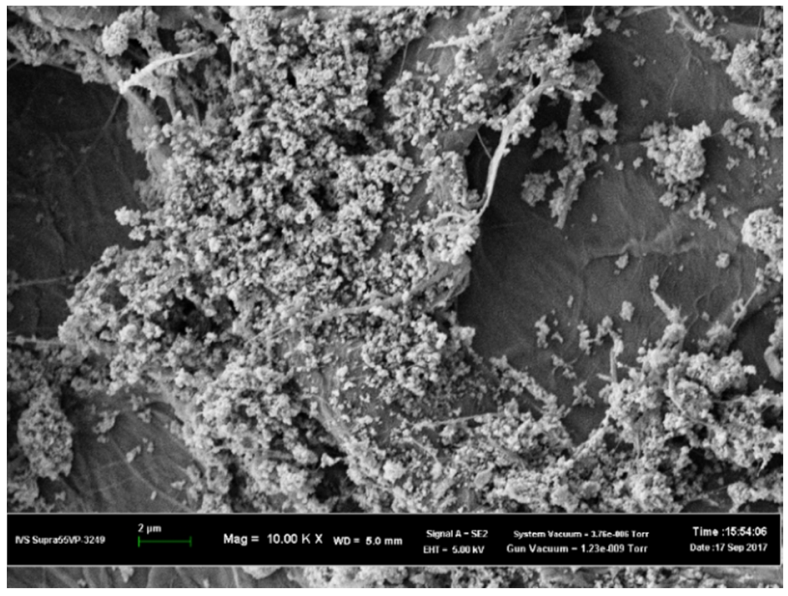

Fig. 4. SEM image of the handsheets where only $\mathrm{TiO}_{2}$ filler was added (magnification 10K)

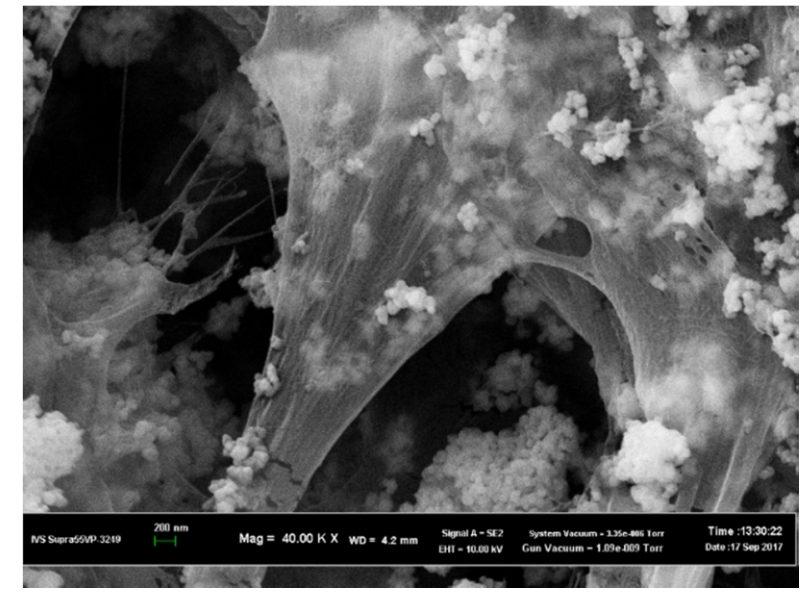

Fig. 5. SEM image of handsheet with $37 \%$ of $\mathrm{TiO}_{2}$ and $5 \%$ of titanyl sulphate based on $\mathrm{TiO}_{2}$ content (magnification 40K)

\section{Conclusions}

The application of titanyl sulphate for manufacturing of $\mathrm{TiO}_{2}$-containing paper was studied. The effects of $\mathrm{pH}$ on $\zeta$-potential and light transmittance of the filtrate for different mixtures of $\mathrm{TiO}_{2} / \mathrm{MCC}$ Titanyl sulphate were shown. It is revealed that the maximum heterocoagulation interaction between the components occurs to the range $\mathrm{pH}$ 4.4-5.6 due to the opposite charges between $\mathrm{TiO}_{2}$ and titanyl sulphate, that leads to maximum retention and other process benefits. The handsheets were analysed conventionally and using SEM. It was shown that titanyl sulphate hydrolysis resulted in the formation of a translucent polymer film within the fibres and $\mathrm{TiO}_{2}$ particles. A small dosage of titanyl sulphate enhanced the strength and the air permeability of the handsheets. A high dosage of 
titanyl sulphate increased the filler retention and the strength of comparative handsheets formed without titanyl sulphate, but in this application of titanyl sulphate is difficult to compete with synthetic polymers in terms of the ash retention. Titanyl sulphate does not help to maintain or to increase the optical properties. It seems prospective the application of low dosages of titanyl sulphate in combination with some fillers to obtain the high air permeability, it could be as advantage for instance for a brown sack paper. Apart from white papers, for this kind of a paper grade the optical properties are less important.

The data obtained shows the difference between additives applied in wastewater treatment and for a paper manufacturing. Conventional flocculants and coagulants that are used to decrease a turbidity level are different to papermaking retention aids because the main idea of manufacturing process is obtaining the end product properties.

\section{References}

1. Handbook of Paper and Board, $2^{\text {nd }}$ Rev. a. Enlarged Ed., Holik H. (Ed.) Weinheim; Wiley-VCH, 2013. 505 p.

2. Ibrahem A.A., Nada A.M.A., El-Saied H. and El-Ashmawy A.E. Angew. Makromol. Chem., 1984, vol. 127, pp. 89-102.

3. Applications of Wet-End Paper Chemistry, $2^{\text {nd }}$ Ed. Thorn, I., Au, C.O. (Eds.) London; Springer, 2009. 232 p.

4. Grzmil B.U., Grela D. and Kic B. Chem. Pap., 2008, vol. 62, no. 1, pp. 18-25.

5. Mamchenko A.V, Gerasimenko N.G., Deshko I.I. and Pakhar' T.A. J. Water Chem. Technol., 2010, vol. 32, pp. $167-175$.

6. Bavykin D.V., Dubovitskaya V.P., Vorontsov A.V. and Parmon V.N. Res. Chem. Intermed., 2007, vol. 33, no. 3-5, pp. 449-464.

7. Bavykin D.V., Savinov E.N and Smirniotis P.G. React. Kinet.Catal. Lett., 2003, vol. 79, no. 1, pp. 77-84.

8. Marques P., Trindade T. and Neto C.P. Compos. Sci. Technol., 2006, vol. 66, pp. 1038-1044.

9. Patent 1718924 A (CN). 2006.

10. van de Steeg, H.G.M., de Keizer A., Cohen Stuart M.A. and Bijsterbosch B.H. Colloids Surf., A, 1993, vol. 70, no. 1, pp. $77-89$.

11. Sandell L.S. and Luner P. Appl. Polym. Sci., 1974, vol. 18, pp. 2075-2083.

12. Delgado A.V., González-Caballero F., Hunter R.J., Koopal L.K. and Lyklema J. Pure Appl. Chem., 2005, vol. 77, no. 10, pp. 1753-1805.

13. Moyer L.S. Bacteriol. Rev., 1935, pp. 531-546.

14. Derjaguin B.V. Discuss. Faraday Soc., 1954 vol. 18, pp. 85-98.

15. Siffert B. and Metzger J.-M. Colloids Surf., A., 1991, vol. 53, no. 1, pp. 79-99.

16. Patent 5705033 (US). 1998.

17. Pelton R.H. and Allen L.H. Colloid. Polym. Sci., 1983, vol. 261, no. 6, pp. 485-492.

Received December 25, 2017

Revised March 6, 2018

For citing: Izmailova N., Shabiev R., Lorentsson A., Saprykina N. Khimiya Rastitel'nogo Syr'ya, 2018, no. 3, pp. 271278. (in Russ.). DOI: 10.14258/jcprm. 2018033603. 